\title{
Evaluation of mucosal displacement and denture settlement for direct vs. indirect attachment incorporation in implant assisted mandibular overdentures
}

\begin{abstract}
Background: One of the attachments used nowadays are the stud Positioner attachments, these attachments can be incorporated in the denture base of the implant assisted overdenture directly inside the patients mouth or indirectly in the laboratory. No studies evaluated the difference in denture-tissue relation in overdentures with attachments incorporation directly or indirectly. Therefore the aim of the present study was to evaluate whether a difference in denture-tissue relation exists between direct or indirect attachment incorporation. Two implants were placed for 7 patients and then an implant assisted overdenture was fabricated, first with indirect attachment incorporation, then with direct attachment incorporation. CBCT scans were performed on the patients with the overdentures in place after 1 week of denture insertion. The area of the mucosa between the fitting surface of the denture and the bone was measured as a guide for denture-tissue relation.
\end{abstract}

Results: The mean anterior mucosal surface area in dentures constructed using indirect attachment incorporation was $21.07 \mathrm{~mm}^{2} \pm 4.89$ while the surface area at point $\mathrm{M}$ in dentures constructed by direct attachment incorporation was $20.53 \mathrm{~mm}^{2} \pm 5.14$. While the mean posterior mucosal surface area in dentures constructed using indirect attachment incorporation was $35.88 \mathrm{~mm}^{2} \pm 3.98$ while the mean posterior mucosal surface area in dentures constructed by direct attachment incorporation was $34.22 \mathrm{~mm}^{2} \pm 3.72$.

Conclusion: Direct attachment incorporation causes greater posterior denture settling than indirect attachment incorporation.
Volume 5 Issue 2 - 2016

\author{
Ahmed MAbdelhamid,' Nazem Assaad, ${ }^{2}$ \\ Ahmed HWeheda' \\ 'Department of Prosthodontics, Faculty of Dentistry, Alexandria \\ University, Egypt \\ ${ }^{2}$ Department of Prosthodontics, Faculty of Dentistry, Lebanese \\ University, Lebanon
}

Correspondence: Ahmed M Abdelhamid, Department of Prosthodontics, Faculty of Dentistry, Alexandria University, Egypt, Email prof.ahmedabdelhamid@hotmail.com

Received: August 18,2015 | Published: September 28, 2016

\section{Introduction}

Edentulism is considered a poor health outcome and may compromise the quality of life. ${ }^{1}$ Treatment of edentulous patients using a conventional complete removable denture is a common clinical undertaking. ${ }^{2}$ However about $30 \%$ of those patients may experience problems with conventional dentures, which include pain during mastication, reduced masticatory ability, as well as insufficient stability and retention of the denture especially in the lower dentures. ${ }^{3}$ To overcome these drawbacks, implant assisted overdentures were introduced for patients who are maladaptive to complete dentures. ${ }^{4}$ In fact, Implant assisted overdentures have become routine therapy because of their relative simplicity, minimal invasiveness, affordability, ease of usage, and minimizing or eliminating movement of the mandibular overdentures. ${ }^{5}$ According to the 2002 McGill consensus $^{6}$ statement on overdentures, a 2-implant supported overdenture may represent the minimum standard of care for the treatment of patients with a completely edentulous mandible. The attachment system used for an overdenture typically consists of a matrix and a patrix. A matrix is defined as the portion of an attachment system that receives the patrix, and the patrix is defined as the extension of a dental attachment system that fits into the matrix. ${ }^{7}$ Irrespective of the type of attachment system, the component that is part of the overdenture prosthesis generally includes a metal housing that mechanically accommodates the replaceable matrix or patrix, which are generally made of a plastic such as nylon. ${ }^{8}$ Several types of attachment systems are available; attachments can be divided into isolated attachments and splinted attachments. The splinted attachments are connected to a bar splinting the two implants. While isolated attachments connect solely to each implant, among the most widely used attachment systems are Ball and Socket attachments, Magnetic attachments and Locator attachments. ${ }^{9}$

There are various techniques for incorporating these attachments to the overdenture. Broadly, they can be classified as direct techniques (performed by the clinician intraorally) or indirect techniques (performed by the technician in the laboratory). ${ }^{10}$ In addition, two necessary elements for description of attachment incorporation techniques in addition to the nature of incorporation are the type of final impression and the stage of incorporation during the overdenture fabrication. ${ }^{11}$ According to these variables, the indirect and direct attachment incorporation techniques could be further divided into seven different techniques. The direct technique has several advantages including simplicity, less expenses, requires less prosthetic elements and allows the patient to retain the prosthesis. However it has the following disadvantages; requires high skill and control of the prosthesis position during the curing of the autopolymerising resin, care must be taken to avoid flow of resin into undercuts, as well as several disadvantages related to the autopolymerising resin such as high shrinkage, water resorption, voids, difficulty in polishing and rapid degradation. ${ }^{12}$ 
While the indirect technique's advantages include reduced chair time, avoidance of contact with the acrylic monomer, optimal polishing, and the use of an acrylic resin with better mechanical properties for the incorporation of the attachments, due to pressure polymerization. Patients suffering from motor control diseases can be better treated using this technique. On the other hand, the main disadvantage is that the impression taking for implants position record through the use of implant transfer copings and analogues may introduce discrepancies and may result in incorporation inaccuracy. ${ }^{13}$ The choice between the direct and indirect technique of attachment incorporation depends on, the choice of prosthetic design, chronology of implant placement with respect to prosthesis, number and position of implants, angulations of implants, prosthetic space availability, the choice of attachment system, the need for processed denture bases, complexity of maxillomandibular relationships, changes in tissues after implant surgery, operator preference, availability of inventory for prosthetic components and finally the cost. ${ }^{11}$ As alveolar ridge mucosa possesses viscoelastic properties, it is expected that the thickness of the tissues as well as the denture settlement may vary according to the technique of attachment incorporation. Measurements of mucosal thickness have been recorded beneath dentures' fitting surfaces as early as the 1940s, when Boucher et al. used a central bearing device known as tiltmeter to measure the thickness the mucosa by assessing denture movement during function. ${ }^{14}$ This was followed by Lytle et al. who measure the thickness on models of tissues with dentures in function for 60 hours. ${ }^{15}$ In addition, other methods included physical invasive methods that used periodontal probes and needles under local anesthesia as well as ultrasonic devices. ${ }^{16,17}$ Finally, in 2003 Compagnoni et al., ${ }^{18}$ used a kinesographic instrument to determine denture movement and thus mucosal thickness. ${ }^{18}$ Most recently, conebeam computerized tomography (CBCT) with low-dose radiation has been explored as a non-invasive technique, which provided an accurate assessment of palatal mucosal tissue thickness. The results were very similar to previous reports that employed physical measurements. ${ }^{19}$ By 2004, Lascala et al. ${ }^{20}$ stated that CBCT is reliable for linear evaluation measurements of structures closely associated with dental and maxillofacial imaging. ${ }^{20}$ Barriviera et al., ${ }^{21}$ and Ueno et al.,22 confirmed the accuracy of measurements of the palatal mucosal thickness using CBCT with all its advantages. ${ }^{21,22}$ Finally, in 2015 Dong et al., ${ }^{23}$ described a method that allowed them to measure the thickness of edentulous mandibular mucosa. In this study, CBCT was used to evaluate and compare the edentulous alveolar mucosal thickness represented by the surface area beneath implant-retained overdentures with direct and indirect attachment incorporation.

\section{Material and methods}

Analysis of the CBCT images of 7 male edentulous patients with ages ranging from 40-65 years was done. The research protocol was approved by the Ethics Committee at Faculty of Dentistry, Alexandria University and all patients were provided with an informed consent. The study was conducted between the periods of June 2014 to June 2015. Inclusion criteria were freedom from any systemic disease, enough basal bone height and width for placement of 2 piece implants, adequate inter-ridge, normal Class I ridge relations, as well as motivated and cooperative patients. Exclusion criteria were patients with impaired neuromuscular control, extremely senile patients (more than 75 years) and finally patients with abnormal jaw relations (Class II or III).

\section{Pre-surgical phase}

Each patient was thoroughly examined using pre-operative CBCT scans with the help of a radiolucent radiographic guide with guttapercha markers to assess the bone at the implant site and choose the suitable implant dimensions for each case. In addition, each patient received an interim complete denture for the length of the study.

\section{Surgical phase}

Each patient received 2 endosseous Superline Dentium implant in the interforaminal region using the conventional 2-stage flap technique using a trapezoidal mucoperiosteal flap. After 3 months the second stage surgery was done where the implants were exposed and healing abutments were screwed in place.

\section{Prosthetic phase}

The prosthetic phase was divided into two stages, after each stage, assessment using CBCT scans were made. These stages were;

a. Constructing a denture with laboratory attachment incorporation (indirect attachment incorporation)

b. Picking up the attachment housing intra-orally. (direct attachment incorporation)

\section{Denture construction with indirect attachment incorporation}

Prior to construction of dentures with indirect attachment incorporation, the healing abutments were removed and replaced by final Dentium Positioner abutments (Figure 1a). Direct final functional impressions were registered at the abutment level to duplicate mucosal compression that would occur in direct attachment incorporation (Figure 1b). After pouring the impressions, the housing were incorporated into the record blocks (Figure 1c\&1d) and denture construction was continued using the conventional techniques with wax elimination, packing and curing (Figure 1e). Finally dentures were delivered and occlusion was adjusted, patients were then recalled after 1 week for $\mathrm{CBCT}$ evaluation to allow for dentures to settle intra-orally.

\section{Direct attachment incorporation of the same denture}

For the sake of standardization, and to limit the number of variables to only one, the same denture used in the previous prosthetic step was used. Housings were removed from the denture (Figure 2a) and replaced on the abutments, normal pick-up of the attachments were performed with an inter-occlusal bite registration silicone guide to allow passive occlusion between the maxillary and mandibular dentures and prevent extra mucosal displacement (Figure 2b).The denture was also inserted and followed up after 1 week for CBCT evaluation.

\section{CBCT assessment}

The method that was used to visualize the denture on a CBCT scan was the Dual Scan Procedure which was done for each patient twice, once with the denture constructed with indirect attachment incorporation, and once with the denture modified with direct attachment incorporation. The dual scan procedure involved the 4 stages: 


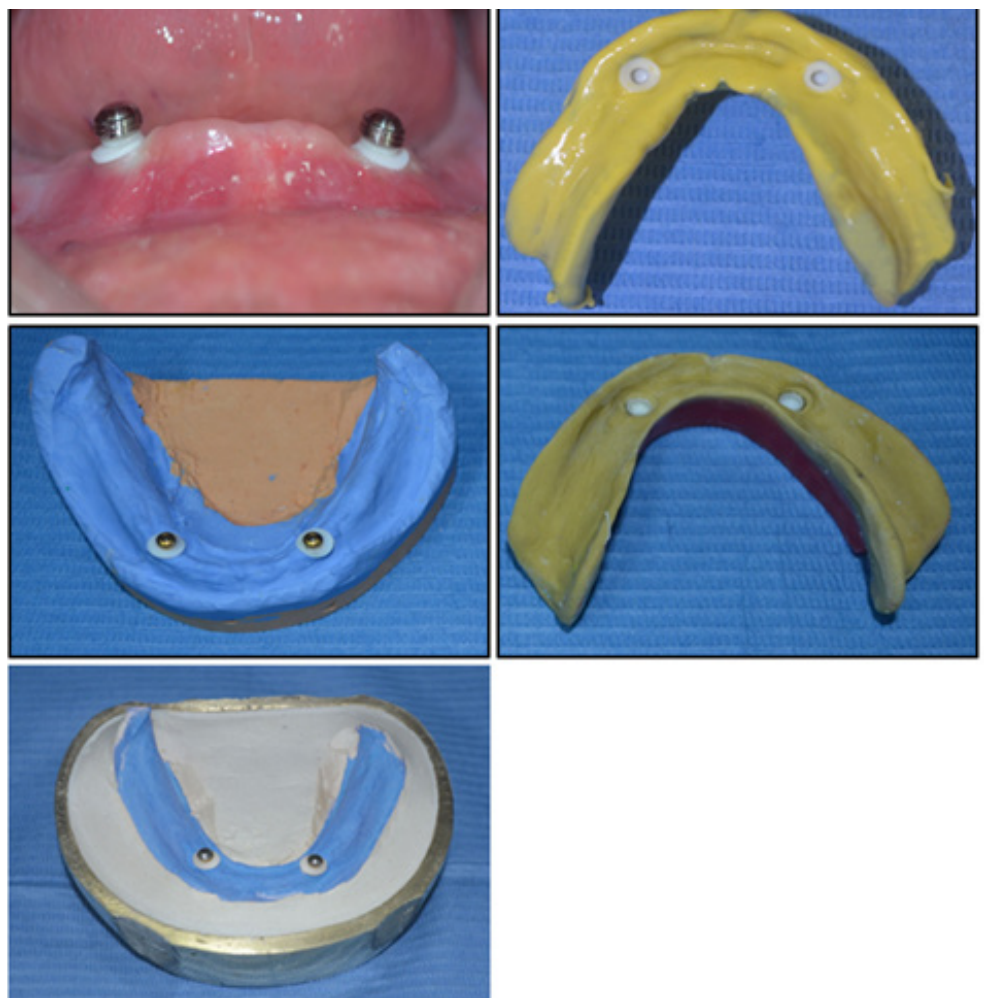

Figure I (A) Positioner housing on abutment; (B) Final impression with housings; (C) Positioner analog in model; (D) Housing incorporated in record blocks; (E) Flasking.

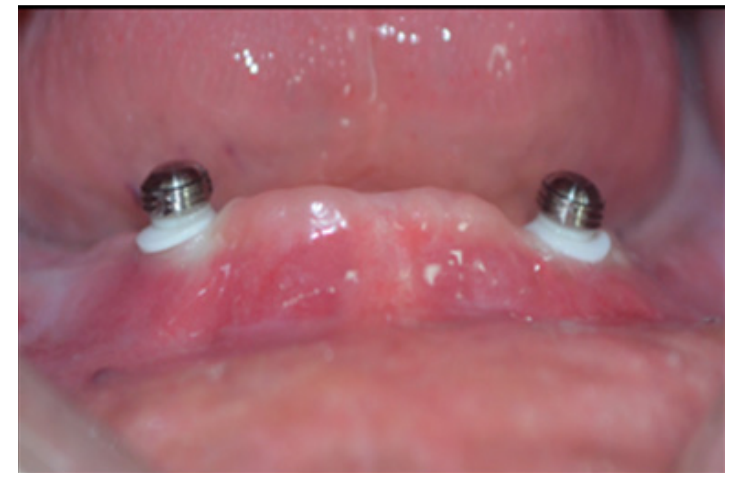

Figure 2 (A) Removal of housing from fitting surface.
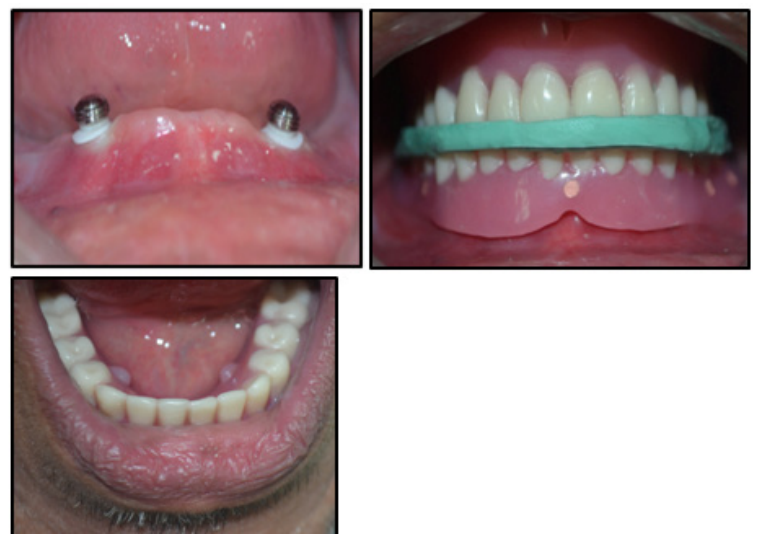

Figure 2 (B) Direct pick-up. 
Preparation of the scan prosthesis: Ten $2 \mathrm{~mm}$ spherical gutta-percha markers were incorporated on the polished surface of the mandibular denture in notches made using number 5 carbide rose head bur, the markers were distributed equally in all directions throughout the mandibular denture and care was taken not to interfere with the metal positioner housing incorporated in the denture, as the housing may cause scatter of radiation affecting the accuracy of the scan (Figure 3a).

Making the first scan (patient and denture scan): To obtain images of the patient and the prosthesis together, the patient was scanned while he or she were wearing the prosthesis (Figure $3 b$ ).

Aligning the patient: For correct alignment, the transaxial CT slice plane was parallel to the occlusal plane of the upper jaw. The relationship of the jaws was stabilized during the scan using a radiolucent silicone bite registration index.

Scanning instructions: The first slice was positioned just beneath the inferior border of the mandible, while the last slice was positioned just above the artificial teeth of the prosthesis, to ensure that the entire prosthesis was included in the scan, the last slice had nothing visible in it. Scanning with a field of view that is too large would have compromised the resolution of the reformatted images. While scanning with a field of view that was too small could have caused the mandible to not fit in all of the axial images. The scan radiation was adjusted at $90 \mathrm{KV}$ and $8 \mathrm{~mA}$. This allowed the patient's bone to appear on the scan.

\section{Making the second scan (denture scan)}

The prosthesis was positioned on cotton in the CT scanner in the same way that it was positioned in the patient's mouth during the first scan. It was particularly critical that the orientation of the appliance in the second scan matched the orientation of the appliance in the first scan to allow for an automatic and accurate match in the software (Figure 3c). The scan radiation was adjusted at $75 \mathrm{KV}$ and $4 \mathrm{~mA}$. This allowed the denture to be visible in the scan

\section{Reconstruction of the images}

Superimposition of the images was done by combining the two DICOM images (image of 1 st and 2nd scan). Superimposition was accomplished by placing the gutta-percha markers on the denture on the gutta-percha markers visible on the 1st scan (Figure 3d).
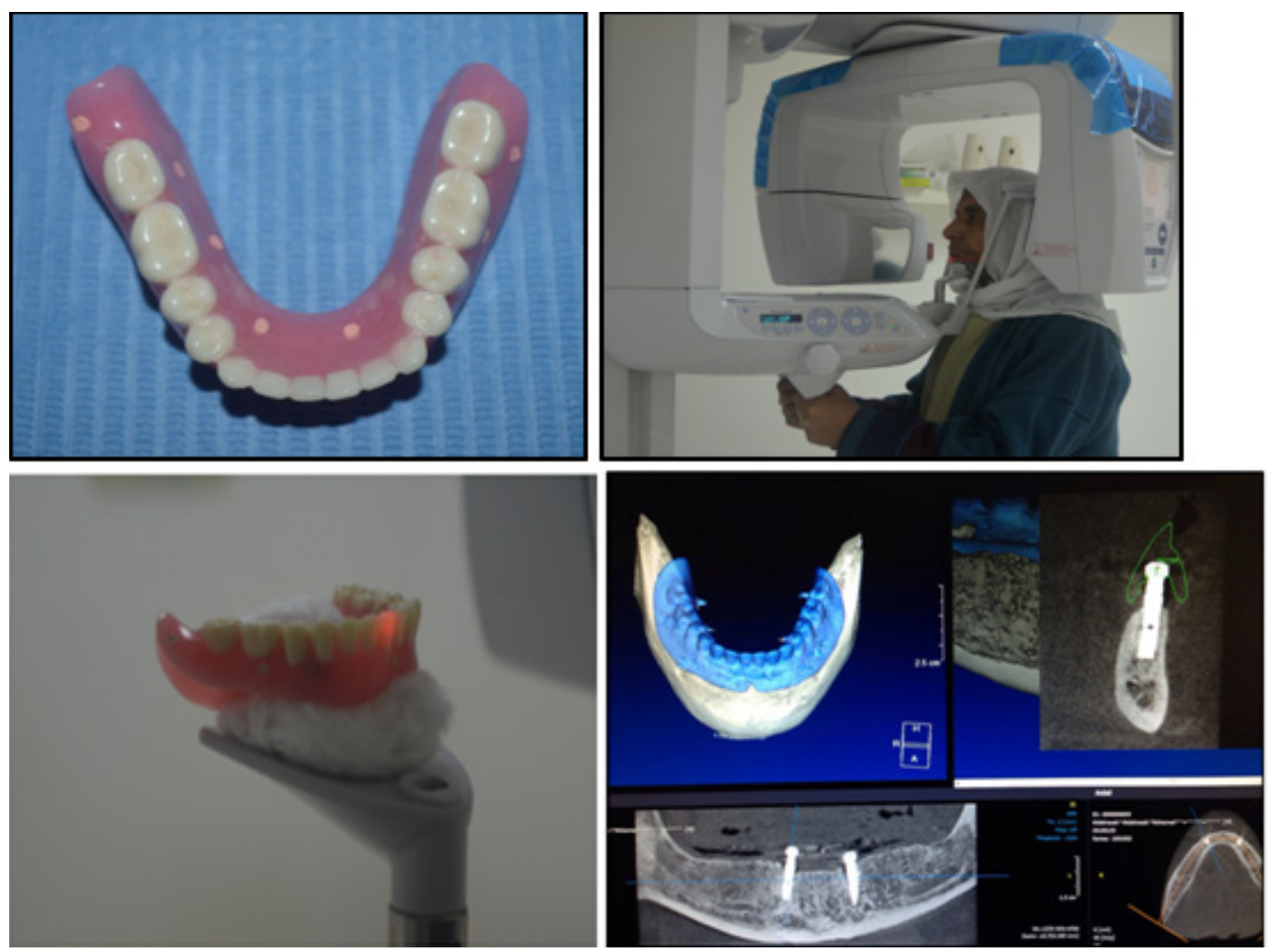

Figure 3 (A) Modified Denture; (B) First Scan; (C) Denture Scan; (D) Reconstructed CBCT image of denture on supporting structures.

\section{Measurements}

On the reconstructed images of the denture in place, the area of the alveolar mucosa between the denture and the alveolar bone were measured on 7 points for each image, this area represented the difference in the amount of denture settling. Point $\mathrm{M}$ on the midline, and 3 points to the right of the midline at $1 \mathrm{~cm}$ intervals $(\mathrm{R} 1,2,3)$ and
3 points to the left of the midline at $1 \mathrm{~cm}$ intervals $(\mathrm{L} 1,2,3)$ (Figure 4). The point $M$ represents the anterior denture settling, while the points R1, 2 and 3 represent the denture settling on the right side, and the points L1, 2 and 3 represent the denture settling on the left side. Collectively, all the $\mathrm{R}$ and $\mathrm{L}$ points represent the posterior denture settling. 


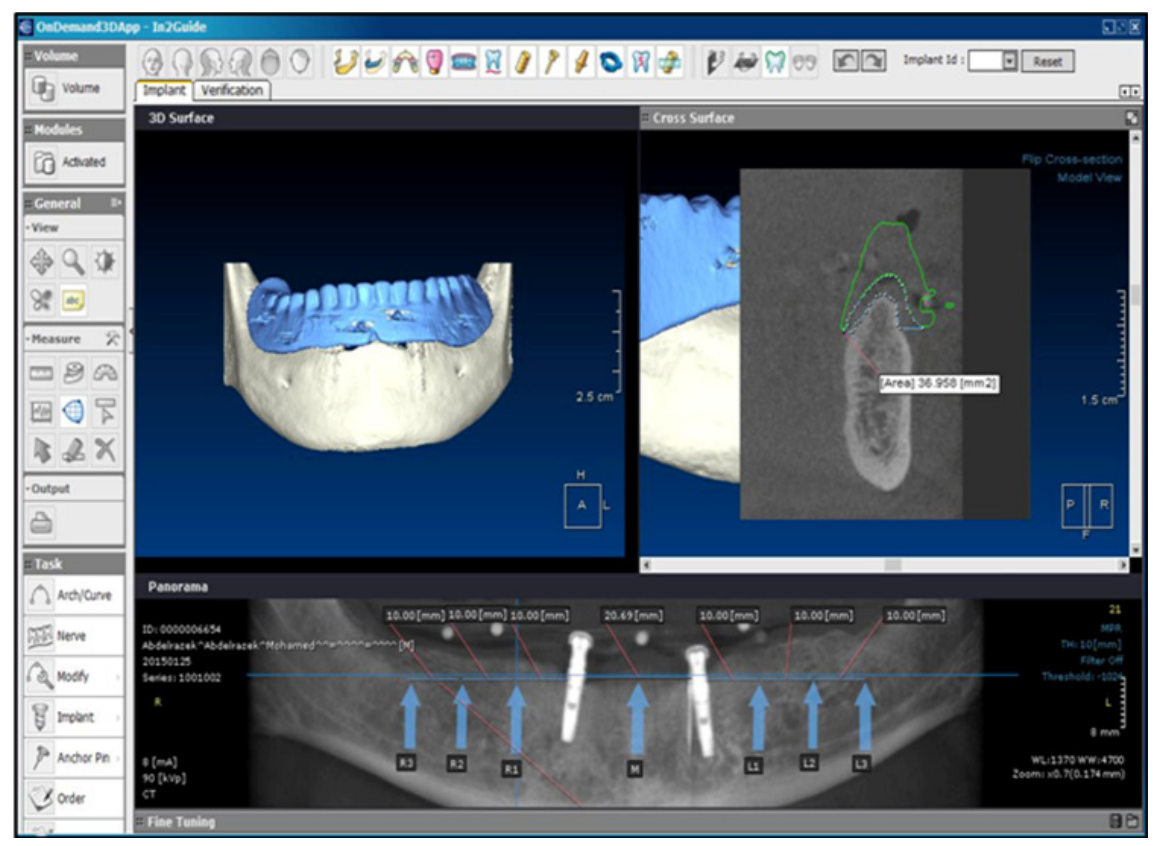

Figure 4 Blue arrows illustrating the 7 points of mucosal surface area measurements.

\section{Result}

The mucosal surface area at point $\mathrm{M}$ represented the anterior denture settling, while the mucosal surface area at points $\mathrm{R}$ and $\mathrm{L}$ represented the posterior denture settling.

\section{Comparison of anterior mucosal surface area (point M)}

The mean mucosal surface area at point $\mathrm{M}$ in dentures constructed using indirect attachment incorporation was $21.07 \mathrm{~mm}^{2} \pm 4.89$ while the surface area at point $\mathrm{M}$ in dentures constructed by direct attachment incorporation was $20.53 \mathrm{~mm}^{2} \pm 5.14$. The results had a large standard deviation which indicated a great variation between different cases, and although the means were different, the paired t test showed no statically significant difference. This indicated that the anterior denture settling did not vary significantly in dentures with indirect and direct attachment incorporation (Table 1).

Table I Mucosal surface area $\left(\mathrm{mm}^{2}\right)$ range, mean and standard deviation at point $M$

\begin{tabular}{|c|c|c|c|c|}
\hline & \multicolumn{2}{|c|}{ Attachment Incorporation } & \multirow{2}{*}{$\mathbf{t}$} & \multirow{2}{*}{$\mathbf{p}$} \\
\hline & Indirect $(n=7)$ & Direct $(n=7)$ & & \\
\hline Point M & & & & \\
\hline Min. - Max. & $15.95-30.55$ & $16.06-0.88$ & 2.231 & 0.067 \\
\hline Mean $\pm S D$. & $21.07 \pm 4.89$ & $20.53 \pm 5.14$ & & \\
\hline
\end{tabular}

\section{Comparison of posterior mucosal surface area}

The mean posterior mucosal surface area in dentures constructed using indirect attachment incorporation was $35.88 \mathrm{~mm}^{2} \pm 3.98$ while the mean posterior mucosal surface area in dentures constructed by direct attachment incorporation was $34.22 \mathrm{~mm}^{2} \pm 3.72$. These results were tested with paired $t$ test for significance and showed a strong statistically significant difference. This indicated that the posterior denture settling in dentures with direct attachment incorporation is significantly greater than posterior denture settling in dentures with indirect attachment incorporation (Table 2).

Table 2 Comparison between posterior mucosal surface area $\left(\mathrm{mm}^{2}\right)$ in dentures constructed with indirect and direct attachment incorporation

\begin{tabular}{llcll}
\hline & \multicolumn{2}{l}{ Attachment Incorporation } & t & P \\
\cline { 2 - 3 } & Indirect $(\mathbf{n}=7)$ & Direct $(\mathbf{n}=7)$ & & \\
\hline Posterior & $29.10-41.73$ & $27.66-39.57$ & $12.557^{*}$ & $<0.00 I^{*}$ \\
Min. - Max. & & & & \\
Mean \pm SD. & $35.88 \pm 3.98$ & $34.22 \pm 3.72$ & & \\
\hline
\end{tabular}

\section{Discussion}

In this study, implant assisted mandibular overdentures were fabricated on two implants in the interforaminal region. The denture settling was compared in overdentures with direct and indirect attachment incorporation, it was evaluated after 1 week of denture insertion to allow for complete settling of the denture. The overdenture was first constructed with indirect attachment incorporation, and the denture settling was evaluated. Then the same denture was modified to have direct attachment incorporation, which was followed by the denture settling evaluation. This kept the number of variables to only one. The denture tissue relation was evaluated using CBCT scans, this was done by measuring the difference in the degree of mucosal displacement between the dentures fabricated by indirect and direct attachment incorporation through measuring the area of the mucosa between the fitting surface of the denture and the bone. The accuracy of CBCT measurement is well documented in literature, where Lagravere et al., ${ }^{24}$ Sherrard et al., ${ }^{25}$ Ye et al., ${ }^{26}$ and Ghoneima et al. ${ }^{27}$ Most recently, a study in 2015 confirmed that the accuracy of measuring the thickness of edentulous alveolar mucosa beneath the fitting surface of a denture using CBCT scans in as accurate as methods that were previously conducted. ${ }^{23}$ The results of the present study revealed that 
there is no statistically significant difference between anterior denture settlements in implant assisted mandibular overdentures fabricated using indirect and direct attachment incorporation. The mean mucosal surface area at point $\mathrm{M}$ in dentures constructed with indirect attachment incorporation was $21.07 \mathrm{~mm}^{2} \pm 4.89$ compared to $20.53 \mathrm{~mm}^{2} \pm 5.14$ in dentures constructed with direct attachment incorporation. This may be attributed to the proximity of the anterior portion of the denture to the implants; therefore the implant abutments limit the degree of settlement. In addition, the settling of lower dentures is in a downward and lingual direction, and therefore in the early stages before anterior ridge resorption, denture settlement is limited. ${ }^{28}$ Results also showed that the posterior denture settling was greater in dentures with direct attachment incorporation than dentures with indirect attachment incorporation and the difference was statistically significant. This may have been attributed to the fulcrum created between the 2 implants, which may have caused rotation of the denture around that fulcrum during the direct attachment incorporation. In addition, the compressibility of the mucosa might have allowed the denture to settle more posterior during the direct attachment incorporation procedure where the patients' biting forces accentuated mucosal compression. Furthermore, the direction of the lower denture settlement (downward and lingual) allows the posterior portion of the denture to move tissue wards. Finally, during the direct pick up, the male components of the Positioner attachment were activated which may have caused the denture to settle more posterior after activation of the attachment..$^{29}$

\section{Conclusion}

From this study, it was concluded that anterior denture settling is not affected by the technique of attachment incorporation in mandibular implant assisted overdenture, while posterior denture settling is greater in dentures with direct attachment incorporation than in dentures with indirect attachment incorporation. Finally, it was confirmed that the dual scan procedures are a reliable method to evaluate denture tissue relation using $\mathrm{CBCT}$ scans.

\section{Funding}

None.

\section{Acknowledgments}

None.

\section{Conflicts of interest}

Authors declare that there is no conflict of interest.

\section{References}

1. Cakarer S, Can T, Yaltirik M, et al. Complications associated with the ball, bar and Locator attachments for implant-supported overdentures. Med Oral Patol Oral Cir Bucal. 2011;16(7):e953-e959.

2. Al Ghafli SA, Michalakis KX, Hirayama H, et al. The in vitro effect of different implant angulations and cyclic dislodgement on the retentive properties of an overdenture attachment system. J Prosthet Dent. 2009;102(3):140-147.

3. Van Waas MA. The influence of psychologic factors on patient satisfaction with complete dentures. J Prosthet Dent. 1990;63(5):545-548.

4. Morais JA, Heydecke G, Pawliuk J, et al. The effects of mandibular twoimplant overdentures on nutrition in elderly edentulous individuals. $J$ Dent Res. 2003;82(1):53-58.
5. Burns DR, Unger JW, Coffey JP, et al. Randomized, prospective, clinical evaluation of prosthodontic modalities for mandibular implant overdenture treatment. J Prosthet Dent. 2011;106(1):12-22.

6. Feine JS, Carlsson GE, Awad MA, et al. The McGill consensus statement on overdentures. Mandibular two-implant overdentures as first choice standard of care for edentulous patients. Gerodontology. 2002;19(1):3-4.

7. Glossary of Prosthodontic Terms. J Prosthet Dent. 2005;94(1):10-92.

8. Nissan J, Oz Ari B, Gross O, et al. Long-term prosthetic aftercare of direct vs. indirect attachment incorporation techniques to mandibular implantsupported overdenture. Clin Oral Implants Res. 2011;22(6):627-630.

9. Alsabeeha N, Payne AGT, Swain MV. Attachment systems for mandibular two-implant overdentures: a review of in vitro investigations on retention and wear features. Int J Prosthodont. 2009;22(5):429-440.

10. Sadig WM. Special technique for attachment incorporation with an implant overdenture. J Prosthet Dent. 2003;89(1):93-96.

11. Bidra AS, Agar JR, Taylor TD, et al. Techniques for incorporation of attachments in implant-retained overdentures with unsplinted abutments. J Prosthet Dent. 2012;107(5):288-299.

12. Daher T. A simple predictable intraoral technique for retentive mechanism attachment of implant overdenture attachments. J Prosthodont. 2003;12(3):202-205

13. Taddei C, Metz M, Waltman E, et al. Direct procedure for connecting a mandibular implant-retained overdenture with ball attachments. $J$ Prosthet Dent. 2004;92(4):403-404.

14. Boucher CO. Studies of displacement of tissues under dentures. J Am Dent Assoc. 1940;27(9):1476-1478.

15. Lytle RB. Soft tissue displacement beneath removable partial and complete dentures. J Prosthet Dent. 1962;12(1):34-43.

16. Wara-aswapati N, Pitiphat W, Chandrapho N, et al. Thickness of palatal masticatory mucosa associated with age. J Prosthet Dent. 2001;72(10):1407-1412.

17. Müller HP, Schaller N, Eger T. Ultrasonic determination of thickness of masticatory mucosa: a methodologic study. Oral Surg Oral Med Oral Pathol Oral Radiol Endod. 1999;88(2):248-253.

18. Compagnoni MA, Souza RFd, Leles CR. Kinesiographic study of complete denture movement related to mucosa displacement in edentulous patients. Pesqui Odontol Bras. 2003;17(4):356-361.

19. Suomalainen A, Vehmas T, Kortesniemi M, et al. Accuracy of linear measurements using dental cone beam and conventional multislice computed tomography. Dentomaxillofac Radiol. 2008;37(1):10-17.

20. Lascala CA, Panella J, Marques MM. Analysis of the accuracy of linear measurements obtained by cone beam computed tomography (CBCTNewTom). Dentomaxillofac Radiol. 2004;33(5):291-294.

21. Barriviera M, Duarte WR, Januário AL, et al. A new method to assess and measure palatal masticatory mucosa by cone-beam computerized tomography. J Clin Periodontol. 2009;36(7):564-568.

22. Ueno D, Sekiguchi R, Morita M, et al. Palatal Mucosal Measurements in a Japanese Population Using Cone-Beam Computed Tomography. $J$ Esthet Restor Dent. 2014;26(1):48-58.

23. Dong J, Zhang FY, Wu GH, et al. Measurement of Mucosal Thickness in Denture-bearing Area of Edentulous Mandible. Chin Med J (Engl). 2015;128(3):342-347.

24. Lagravère MO, Carey J, Toogood RW, et al. Three-dimensional accuracy of measurements made with software on cone-beam computed tomography images. Am J Orthod Dentofacial Orthop. 2008;134(1):112-116. 
25. Sherrard JF, Rossouw PE, Benson BW, et al. Accuracy and reliability of tooth and root lengths measured on cone-beam computed tomographs. Am J Orthod Dentofacial Orthop. 2010;137(4):S100-S108.

26. Ye N, Jian F, Xue J, et al. Accuracy of in-vitro tooth volumetric measurements from cone-beam computed tomography. Am J Orthod Dentofacial Orthop. 2012;142(6):879-887.

27. Ghoneima A, Kula K. Accuracy and reliability of cone-beam computed tomography for airway volume analysis. Eur J Orthod. 2013;35(2):256-261
28. Landa JS. Trouble shooting in complete denture prosthesis: Part X. Nerve impingement and the radiolucent lower anterior ridge. J Prosthet Dent. 1961;11(3):440-444.

29. Vahidi F, Pinto-Sinai G. Complications Associated with Implant-Retained Removable Prostheses. Dent Clin North Am. 2015;59(1):215-226. 